\title{
O Holocausto como aprendizagem: As particularidades do filme "La Vita é bella" traduzidos em sala de aula
}

\author{
Letícia Oliveira Borges* \\ Luiz Paulo da Silva Soares ${ }^{* *}$
}

Resumo: $O$ presente artigo tem por intento abordar de forma sucinta uma possível utilização do filme La Vita é Bella em sala de aula. Através do filme é possível abordar o Holocausto de uma maneira instigante e compreensível no que diz respeito a alguns aspectos em destaque na História sobre o tema. Dessa forma, este trabalho traz em seu cerne, dados sobre o tema holocausto, sua relevância como estudo nos livros didáticos de história e por fim, um singelo modelo de utilização do filme em sala de aula.

Palavras-Chave: Holocausto; Ensino-aprendizagem; Cinema-História.

Abstract: The intent of this article is to deliver succinctly and clearly a possibility of using the film La Vita é Bella in classes. Through the film is possible to approach the Holocaust in a more compelling and understandable way in regard to some aspects highlighted in this theme's history. Therefore, this work brings data exposure about Holocaust and its relevance in history textbooks and finally a simple example of this movie uses in a classroom.

Keywords: Holocaust; Teaching and learning; Movies-History.

\footnotetext{
* Mestranda em História pela Universidade Federal do Rio Grande - FURG.

** Mestrando em Educação na Universidade Federal do Rio Grande - FURG
} 


\section{Considerações Iniciais}

Com as experiências vividas, o homem passa a impor determinadas ações a sua vivência diária, isto significa estabelecer vínculos. Sua relação com o passado se dará de diversas formas a partir dessas interpretações experimentais. Usualmente, as experiências ruins são decifradas com ações e ideias que se esquivam de repetições do infortúnio. Um claro caso desses é percebido através daqueles que vivenciaram um Holocausto. Poder-se-ia citar vários nomes, dentre eles Victor Franklin, Michel Dymetman, Samuel Klein, Salomon Smolianoff, entre outros, que seguiram suas vidas e transformaram seus dias mesmo tendo presenciado momentos como o do Holocausto.

"Considerado por muitos como o acontecimento mais degradante e desumano que figurou no cenário da $2^{\mathrm{a}}$ Grande Guerra, o Holocausto causa inquietação, dúvida e indignação, produz controvérsias entre os estudiosos do assunto" (REGERT, 2009: 1). Revisionistas ${ }^{1}$ e negacionistas $^{2}$ procuram por em dúvida a intensidade, dimensão e autenticidade dos horrores do Holocausto. No entanto, neste ensaio não nos deteremos a exemplificar nenhuma das duas correntes, mas sim, descrever de forma sucinta o que foi o Holocausto e como se desenrolou tal fato histórico, examinando um filme em especial "A vida é Bela de Roberto Begnini”.

O Holocausto foi à perseguição política, étnica, religiosa e sexual estabelecida durante os anos em que Adolf Hitler governou a Alemanha nazista. Segundo um conjunto de convicções filosóficas, sociais, políticas e etc. dos nazistas, a Alemanha deveria sobrepujar os obstáculos que impediam a formação de uma nação constituída por seres superiores. Segundo essa mesma ideologia, os legítimos alemães eram descendentes de arianos, um antigo povo que - segundo os etnólogos europeus do século XIX - possuíam pele branca e conferiram à civilização européia.

À vista disso, para que a supremacia ariana fosse alçada pelos alemães, o governo de Hitler inicia sua arguição de ódio contra todos aqueles que estorvavam a pureza racial dentro do território alemão. Segundo a exposição nazista, a maioria culpada por esse impedimento do processo de eugenia étnica eram os ciganos e, principalmente, os judeus.(Refazer)Sendo

\footnotetext{
${ }^{1}$ São os chamados adeptos da teoria do Revisionismo - que prega a revisão de idéias, doutrinas, valores, fatos históricos. No caso do Holocausto os revisionistas questionam a veracidade do acontecimento, ou sua intensidade e proporção.

${ }^{2}$ Adeptos da doutrina que nega o genocídio judeu durante a Segunda Guerra Mundial, bem como afirma que as câmaras de gás são uma grande invenção dos judeus.
} 
assim, Hitler passa então a perseguir e forçar o isolamento em guetos do povo judeu nos territórios de governo alemão.

Com o início da Segunda Guerra Mundial, os nazistas criam campos de concentração onde judeus e ciganos são forçados a trabalhar e "viver". Nos campos, os concentrados eram obrigados a trabalhar nas indústrias essenciais ao sustento da Alemanha durante a Segunda Guerra. Ademais, os instalados nos campos viviam em condições horríveis, possuíam uma alimentação precária, sofriam torturas e eram usados como cobaias em experimentos científicos.

Não somente judeus foram perseguidos, mas outros grupos sociais também foram vítimas do governo nazista de Hitler, e por isso, foram levadas aos campos de concentração. Homossexuais, doentes mentais, eslavos, opositores políticos de Hitler, pacifistas e grupos religiosos tais como as Testemunhas de Jeová, sofreram com o Holocausto.

Portanto, é fácil demonstrar que o holocausto espraiou suas forças sobre todos os grupos étnicos, sociais e religiosos que eram conjecturados como um malefício ao governo Hitlerista.

Ao final do conflito da Segunda Guerra Mundial, e com a derrota da Alemanha, muitos oficiais alemães decidiram assassinar os as pessoas que foram levadas aos campos de concentração. A medida foi tomada com o objetivo de acobertar as atrocidades praticadas nos campos espalhados pela Europa. No entanto, tropas francesas, britânicas e norte-americanas conseguiram expor a hecatombe promovida pelos alemães nazistas.

Pós rendição dos exércitos alemães, os principais líderes foram julgados por uma tribuna internacional na cidade alemã de Nuremberg. Ao final do julgamento a maioria foi condenada à morte sob a alegação de práticas criminosas de guerra. Em nossa contemporaneidade existem muitas obras, museus e instituições mantidas com a pretensão de lutar contra a propagação do ódio racial e do nazismo.

Sendo assim, através desses breves apontamentos se propõe analisar o filme "La vita é bella de Roberto Benigni" (1998) traçando uma co-relação com a história dita "oficial” e os dados dramatizados através da película. Trabalharemos ainda características de como esse assunto é visto nos livros didáticos e como se pode trabalhar o assunto através do filme relatado.

\section{Contexto e explanação acerca do filme}


A película tem início com a chegada do personagem Guido Orefice (Roberto Begnini) a Arezzo em 1939 - representa de certa maneira uma guinada para os judeus italianos. Até aquele momento, Benito Mussolini, que governara a Itália e era aliado da Alemanha e de Adolf Hitler na Segunda Guerra Mundial, na maioria das vezes manifestava-se contra as teorias nazistas germânicas sobre a suposta superioridade da raça ariana, chegando até mesmo a escarnecer o dito em público.

Mussolini alia-se militarmente aos alemães, mudando, portanto, o discurso e adotando práticas antissemitas em território italiano.

Práticas, que no filme sob a direção de Benigni, transformaram-se em cenas irônicas e porque não dizer cômicas. Um exemplo, baseado na vida real que aparece no filme, são as placas fixadas à frente das lojas dizendo ser proibida a entrada de judeus e cachorros - um escrito comum em vários estabelecimentos italianos depois de 1938.

Mesmo que a perseguição resultasse na retirada forçada de muitos judeus italianos de empregos e escolas públicas e de uma série de outras funções, eles passaram a ser efetivamente executados ao final da Segunda Guerra Mundial.

Com a proximidade do fim do conflito, em 1943, os italianos tentaram, de forma apartada, negociar a paz com Aliados e, em represália os alemães ocuparam parte do país e começaram a enviar judeus que ali residiam para campos de concentração. Conforme demonstrado com o personagem Guido e sua família na segunda parte do filme.

Uma das classes com maior número de sobreviventes foram os judeus italianos. Que ao término da guerra somaram um razoável contingente de sobreviventes oriundos dos campos de extermínio. No entanto, a estimativa ao final da guerra era que cerca de 6 milhões de judeus tinham sido mortos por nazistas alemães e seus colaboradores no que então se chamou Holocausto.

É compreensível captar o porquê o drama "A vida é Bela", dirigido, coescrito, coproduzido e protagonizado pelo italiano Roberto Benigni, foi um dos filmes mais premiado e apreciado na década de 90.

No que diz respeito ao público, foi uma obra que provocou emoções desmedidas incorrendo facilmente no gosto das massas. Críticos, mídia, festivais internacionais, etc., esse trabalho renovou abordagem de temas já explorados - entre eles, o horror dos campos de concentração nazista - de maneira popular, cômica e de imediata identificação.

Benigni inicia seu roteiro como um conto de fadas e encerra como uma fábula. A primeira parte do filme é cercada de beleza e suntuosidade do ambiente das situações que 
proporcionam um fundo para a paixão de Guido Orefice (Benigni) e Dora (Nicoletta Braschi - mulher de Benigni na vida real). Na segunda metade, que é o verdadeiro nervo criativo e emocional da obra, a ação é envolta a um campo de concentração e extermínio, no qual Guido, agora pai, inventa histórias para desviar a atenção de seu filho Giosué (Giorgio Cantarini), do contexto terrível que o cerca.

A relação pai/filho dá-se sob o sacrifício, que explora a superação pela via da ilusão (nada mais cinematográfico!). Em sua trama espalhafatosa, Guido transforma-se em bálsamo momentâneo para todos á sua volta.

Benigni maneja bem o clichê do protagonista mirim, que provoca reações essenciais no espectador, de empatia, comoção, proteção, saudosismo e por fim, a catarse. O cineasta quis comover a muitos, e com certeza assim o fez.

O longa metragem abre espaço para diversas análises, interpretações, sobretudo no espírito humano que o mesmo empreende. É uma visão otimista sobre a vida. Porém ilude-se quem pensa que a película mantém a visão angelical do título.

Como se pode perceber o filme consome lentamente o espectador, sem pedir licença, e influencia a cada minuto, conquistando exageradamente o impossível, trazendo a tona sorrisos tímidos que escapam o tempo todo. É um convite à felicidade, à alegria, ao otimismo. Descobre-se, no desenrolar da trama, que a ingratidão da vida é um tema recorrente, porém não explícito. No entanto, os sorrisos sinceros dão lugar à apreensão. Um rapaz (Guido) que indiscutivelmente considerou a felicidade como guia do seu cotidiano, vê-se, em certo ponto do filme, diante do drama do mundo e seu em particular e ainda assim decide dar beleza a face sincera e ingênua do pequeno menino condenado à pagar por aquilo que não cometeu, e demonstrar aos adultos aquilo que deveriam ser. O amor, ao que tudo indica, é a beleza que se esconde por trás de uma relação inesperada.

Todos imaginam o que pode acontecer num campo de concentração. Todos que têm a percepção do mal sejam qual for à finalidade de qualquer intenção de guerra. A capacidade de rejeição e destruição à outra etnia, ou grupo religioso inexiste ao inocente menino. Ao assistir o filme se tem a percepção da finalidade da história, sabe-se das consequiências e, é de se invejar alguém que está à beira da morte, no entanto não tem consciência do fato é, no mínimo, controverso. E isso com certeza choca.

É por isso que filmes tem o benefício de inventar/criar hipoteticamente uma situação representativa com maior ênfase naquilo que a vida real por alguns momentos consegue demonstrar; e a "Vida é Bela" parece usufruir desse mecanismo a seu favor. A consciência da 
morte para Guido é iminente, mas para Giosué se passa como uma mera suspeita. O jogo criado pelo pai torna o restante da vida de seu filho puro e inocente, misturando temperos de irrealidade para representar uma realidade distorcida. Ao se reconhecer essa singularidade verdade, a vida deixa de ser bela.

Um tema como este deve ser rememorado incessantemente em sala de aula. Docentes tem o privilégio de ensinar essa história de maneira lúdica para que o acontecimento não seja esquecido. Para tanto é necessário ver o que os livros didáticos dizem a respeito do assunto.

\section{O Holocausto nos livros didáticos de História}

Nos livros didáticos, o tema Holocausto dependendo do livro é pouco abordado ou as vezes nem isso. Selecionamos cinco obras distintas entre ensino fundamental e médio. Três obras pertencentes ao fundamental e duas do ensino médio. A primeira obra analisada diz respeito à coleção pertencente ao Projeto Araribá referente ao PNLD 2011-2013. A mesma, ao ser analisada superficialmente no que tange o ensino do Holocausto, deixa um pouco a desejar, devido a não abordagem do tema propriamente dito. Em uma parte do capítulo intitulada Em Foco, os autores abarcam temas diversos em pequenos textos. Perícopes que abrangem Os guetos, as Memórias de Auschwitz, e o O levante de Varsóvia.

Já no exemplar da coleção História: Das cavernas ao terceiro milênio, também não atende as expectativas, porém não tanto quanto ao exemplar da coleção do Projeto Araribá, pois neste, as autoras abordam o tema através da política de solução final que fora implementada pelos alemães e que tinha por intento o extermínio em massa de judeus. Além disso, o capítulo sobre a Segunda Guerra é aberto com uma citação de Primo Levi, intitulado É isto um homem?Cujo qual o mesmo faz uma análise das barbáries da Guerra.

Na continuação da análise, o exemplar da coleção História, Sociedade \& Cidadania de autoria de Alfredo Boulos Júnior, traz em uma parte distinta do capítulo o Para Refletir. Neste ponto o autor aborda a Questão adotada pelos nazistas conhecida como Solução Final: A fábricas de morte de judeus. Em pouco mais de uma página e meia o autor fala dos campos de concentração, além de dar um panorama de como era realizada a separação das pessoas, onde uma das partes composta por idosos, doente e crianças que eram imediatamente enviadas para a morte por meios das câmaras de gás e as outras que eram destinadas a realizarem trabalhos braçais forçadamente. Tal texto expõe de forma simples e geral como era a chegada dos judeus nos campos de concentração e extermínio, informando como que estes 
eram tratados pelos nazistas alemães (é importante ressaltar que no filme analisado neste ensaio essa parte ocupa uma cena significativa no desfecho da trama). Em outra parte do livro o autor utiliza o texto como fonte. O mesmo insere o diário de Anne Frank, onde traz um trecho do diário da menina judia que ficou escondida dos nazistas durante dois anos no sótão da casa. Este trabalho primoroso é interessante ser trabalhado e analisado com os discentes pois o próprio filme examinado neste texto reflete esse aspecto de uma criança sendo escondida em determinados locais no campo de concentração.

Entre os livros de ensino médio, a coleção Por Dentro da História, os autores abordam o tema Holocausto em uma parte da unidade descrita como Você Sabia? Abarcando o que foi o mesmo, quando iniciou, quais as etapas, quem era dizimado e onde aconteciam as exterminações.

E por último o Livro Único História do Ensino Médio do PNLD 2009-2011, aborda o Holocausto da mesma maneira que o exemplar anterior, somente com um diferencial, os autores indicam filmes para exemplificar o que o mesmo está dizendo. Entre os filmes indicados encontram-se: A lista de Schindler (1993) e O pianista (2002), além da indicação de leitura do Diário de Anne Frank.

Diante da análise feita, fica a pergunta: como o docente pode trabalhar esse assunto tão desafiador e horrorizante em sala de aula, afinal é um dos tantos aspectos que não devem ser negligenciados aos discentes em formação de serem cidadãos conscientes de seu papel no desenrolar de sua cidadania. Queremos propor um método através do filme aqui pormenorizado.

\section{Trabalhando o Holocausto em sala de aula através do filme "A vida é bela"}

Primeiramente, cabe ressaltar que o Holocausto por ser um tema abrangente e por estar inserido em um contexto amplo como a Segunda Guerra Mundial, precisa ser trabalhado de forma simples, e agradável, embora o tema a ser estudado não seja algo fácil de se explorar, devido a crueldade desmedida e suas repercussões truculentas ao longo da história.

Diante disso, devem ser planejados todos os momentos da aula, e sempre se deve ter um segundo plano caso algo dê errado. Assim, pode ser trabalhado o Holocausto através de charges, propagandas de época, depoimentos de sobreviventes, filmes, documentários, imagens, enfim existe uma infinidade de materiais que podem ser utilizados em sala de aula. 
No entanto queremos nos deter no ensino através da película "La vita é bella". Para ensinar o Holocausto através desta iconografia é necessário primeiro fazer uma ambientação do assunto, como por exemplo, explicitar o que é o Holocausto, quando ocorreu, por que ocorreu, de que forma, quais os meios utilizados, quais as ideologias que impulsionaram nesta fatídica história, e que acabou com a vida de mais de seis milhões de judeus, mas não somente estes, como também ciganos, homossexuais, entre outros. E que um dos pressupostos para essa barbárie é que segundo o Fihrer todos que não fossem puros, ou seja, que não fossem arianos deveriam ser exterminados, e a riqueza das populações judaicas eram tidas como causa do fracasso econômico da Alemanha. O terceiro Reich comandado por Hitler e na Itália o fascismo comandado por Benito Mussolini. Este último por ser aliado de Hitler na Guerra, devido o mesmo ter prometido territórios para a Itália este começou o regime fascista na Itália. Isso pode ser conversado com os alunos antes ou depois da película.

Além disso, o professor deve fazer links do filme com a realidade da época, como o trabalho forçado, as mortes, as capturas dos judeus, o transporte, a separação dos mesmos nos campos de concentração a utilização da mão de obra forçada, as pichações em comércios judeus, as propagandas colocadas nas portas de estabelecimentos dizendo proibidos Judeus entre outros aspectos. Na verdade o docente deve ensinar todo o contexto, desde o inicio da ditadura implementada por Hitler na Alemanha, o processo de perseguição, antes e durante a guerra, e também o pós-guerra. Mesmo que para isso, o professor precise utilizar de meios estatísticos para exemplificar o que realmente aconteceu. Por isso,

Cabe ao professor criar situações que deixem os alunos intrigados incentivando-os a fazer pesquisas, indagar, valorizando o resgate da memória histórica e o debate de idéias. O desafio da escola está em reconhecer a diversidade etnocultural procurando superar qualquer tipo de discriminação. Dependendo do conteúdo selecionado por cada disciplina, o professor poderá orientar o aluno a fazer entrevistas com sobreviventes do Holocausto, pesquisar documentos e fotografias, selecionar matérias de jornais noticiando os fatos e, até mesmo, incentivá-lo a produzir um texto ou uma exposição iconográfica, produtos a serem apresentados em um seminário. (CARNEIRO, 2007: 4).

Por isso que utilizar um filme para explicar o que foi o Holocausto propicia aos discentes uma compreensão dos preconceitos, existentes no mundo como, por exemplo, o racismo, o antissemitismo e também podemos dizer dos estereótipos que foram dados a determinados grupos da sociedade. Diante disso,

Os estudos sistemáticos sobre genocídio, nazismo e antissemitismo nos oferecem amplas oportunidades para refletirmos sobre o caráter inato da 
intolerância. Daí a história do Holocausto, enquanto genocídio singular na História da Humanidade, ser um tema instigante para avaliarmos os limites da barbárie. Se avaliado sob múltiplos aspectos, o Holocausto pode alertar sobre as consequências catastróficas dos regimes totalitários e autoritários, assim como o perigo das idéias racistas. Tanto o debate sobre nazismo como o Holocausto passam, necessariamente, pela compreensão dos Direitos Humanos, possibilitando-nos refletir sobre a responsabilidade do Estado pela preservação da vida do cidadão. Através de uma análise crítica das teorias e práticas da exclusão implementadas pelo Terceiro Reich a partir de 1933 (e que culminaram com o extermínio de milhões de judeus e não judeus) podemos desenvolver atitudes que favoreçam a convivência democrática e a construção da cidadania. (CARNEIRO, 2007: 3 e 4).

Após realizar isto, o mesmo deve jogar a vez para os alunos, perguntando o que eles acharam do filme? Porque que ele tem esse título? O que o diretor quis fazer quando lançou este filme? Por que ele é abordado desta maneira, diferente dos outros filmes que trabalham com a temática do Holocausto. Quais as características ficcionais do filme e quais características que os mesmos acham que são verídicas e porque da escolha. E a partir disso começar a destrinchar o filme por meio do tema da aula que é o Holocausto. Incentivar aos alunos a realizarem projetos de pesquisa, como por exemplo, como era a vida nos guetos, a situação das crianças durante as perseguições em outros pontos que podem ser explorados.

Trabalhar com um filme em sala de aula não deve jamais ser para remediar uma situação, por isso o planejamento é essencial. A utilização do filme em aula é para fazer com que os alunos entendam o que representou o Holocausto durante a II Guerra Mundial, além é claro de propiciar aos discentes que analisem o filme e redijam um texto sobre o tema trabalhado. Os alunos devem assistir ao filme e analisar alguns pontos chaves do mesmo, como por exemplo, o que o personagem faz para não deixar transparecer os horrores da guerra ao seu filho, entre outros pontos que foram decisivos para no desfecho da história. Embora o filme não retrate tal qual como era em um campo de concentração, pois a obra é muito mais ficcional do que propriamente histórica, os alunos devem realizar comparações do filme com o conteúdo, além de expor o que falta neste. Posteriormente a isso, começar a questionar o filme e o conteúdo ao mesmo tempo, juntamente com os discentes. Procurar entender todos os meandros envolvidos na história.

Podemos delinear aqui alguns aspectos interessantes que podem ser trabalhados. No filme o pai do menino inventa uma história de um jogo, onde ele tenta acobertar as atrocidades que estavam sendo feitas por meio deste, para que seu filho não testemunhasse os horrores da guerra. Fazendo com que toda vez que ele tinha que ir trabalhar ficasse escondido para que ninguém o encontrasse. Neste ponto podemos relacionar com a História de Anne 
Frank que ficou escondida dos nazistas no sótão de casa durante dois anos, no entanto, a mesma acabou sendo encontrada e posteriormente morta.

Outro destaque pode ser os minutos finais do filme que demonstram os alemães dizimando os concentrados devido a sua derrota e sendo assim ofuscando as atrocidades cometidas. Isso pode ser relacionado quando o Pai e o menino Giosué saem do lugar onde dormem e o pai faz com que o menino fique escondido em uma caixa e diz ao garoto para não sair dali, enquanto o mesmo vai procurar a princesa, que é sua esposa, e mãe do menino. Nesta parte Guido enquanto procura sua esposa é capturado por fascistas e levado a um lugar deserto, onde tiram a vida do mesmo. Enquanto acontecia isso, seu filho ficara sozinho no esconderijo em que o pai havia colocado. Quando tudo termina, o menino sai do esconderijo quando aparece um tanque de guerra norte-americano, aparentando que o jogo que Guido havia inventado realmente acontecia naqueles tempos difíceis, e que o vencedor era o menino. A partir dai o menino é carregado no tanque onde logo em seguida encontra sua mãe.

Outro ponto que no filme faz alusão à realidade da perseguição aos judeus são as pichações nas paredes e portas dos comércios destes. E que por consequência são também colocados cartazes nas portas de outros comércios indicando a proibição da entrada de judeus nos estabelecimentos.

Além disso, pode-se destacar também o tratamento dado aos judeus nos campos de concentração, como por exemplo, água e comida, que era muito pouca para muita gente. Devido a isso muitos prisioneiros morreram de fome, desidratados, por falta de condições mínimas de higiene. E que no filme aparece em um diálogo entre pai e filho sobre a escassa alimentação.

Outro fator importante é a exaltação de que a raça ariana é a raça superior. Hitler por meio de propagandas, cartazes, discursos exaltava a raça ariana, asseverando que esta era a raça suprema, a única digna de sobreviver e os judeus não, por isso a pregação do ódio contra os judeus, homossexuais, ciganos, testemunhas de Jeová, os quais segundo os nazistas não eram dignos de viverem, por isso, precisavam ser eliminados. Para isso, a campanha hitlerista que fora adotada e que ficou conhecida por "Solução Final", ficou encarregada da execução em massa destas pessoas por meio de câmaras de gás, ou campos de extermínio. Outra vez o filme explora essa abordagem de forma significativa no decorrer da trama.

A película deixa claro como eram transportadas essas pessoas nos trens amontoadas, além de evidenciar como era realizada a separação entre homens, mulheres, pessoas idosas e crianças. Estes últimos geralmente eram enviados direto para as câmaras de gás, pois davam 
muito trabalho, os outros eram destinados a trabalhos forçados, além de ficarem em lugares extremamente úmidos e com cheiro ruim. A mesma ainda nos dá um panorama, mostrando em uma ou duas cenas com inúmeros cadáveres empilhados. algo que era muito comum durante a segunda guerra com a dizimação de milhares de pessoas nos campos de concentração. Dentre outros aspectos que podem ser elencados.

\section{Conclusão}

Diante do que aqui foi discutido é preciso pensar o momento em que se vive. Um tempo em que falar a qualquer discente é cada vez mais complicado. Ainda mais assuntos que despendem sobre vidas de pessoas que ainda se fazem presentes no nosso mundo.

De fato, discentes comprometidos com a história e singularmente ao Holocausto, tema desse ensaio, devem observar tal verbalização de Luis Milman “[...] o Holocausto não diz respeito apenas aos judeus. Ele é parte da história humana e sua incidência na história demandada uma capacidade de análise crítica sobre os alicerces da própria civilização moderna e seus valores" (MILMAN, 2013). O acesso ao Holocausto pode se dar através da condição dos homens e mulheres modernas e ocidentais que desejam rememorar a história para que a mesma não seja esquecida nem aconteça tal fato novamente. É responsabilidade dessa geração e das futuras manter viva a lembrança do Holocausto.

O apelo está em cada filme que aborda o assunto. Algo que traz várias reflexões aqueles que assistem a documentários, películas e etc. O Holocausto se encerrou há décadas, no entanto é necessário continuar o estudo e a pesquisa do mesmo para que acontecimentos como os apresentados pela mídia do cotidiano na guerra do Oriente Médio, por exemplo, não sejam vistos como meros acontecimentos, mas que possam ser revistos e pensados. É preciso investigar para promover o conhecimento. A memória precisa ser sempre explorada, para que assuntos como esse se façam verdadeiros a ciência histórica em favor da educação.

\section{Referências Bibliográficas}

BOULOS JUNIOR, Alfredo. História - Sociedade \& Cidadania. $9^{\circ}$ ano - São Paulo: FTD, 2009.

BRAICK, Patrícia Ramos. Mota, Myriam Becho. História: das cavernas ao terceiro milênio. $2^{\mathrm{a}}$.ed. $9^{\circ}$ ano - São Paulo: Moderna, 2006. 
CARNEIRO, Maria Luiza Tucci. Nazismo e Antissemitismo, teorias e práticas da exclusão. In: Anais da IV Jornada Interdisciplinar sobre o Ensino do Holocausto. "A Arte de ensinar e lembrar a História do Holocausto", São Paulo: USP, 2007.

LA VITA é bella. Direção: Roberto Benigni. Imagem Filmes, 1997. 1 DVD (116min), son., color.

MILMAN, Luis. $O$ Holocausto: verdade e preconceito. Espaço Acadêmico. Disponível em: http://www.espaçoacademico.com.br/043/43cmilman.htm. Acesso em: 29 dez. 2013.

REGERT, Vera Silveira. Releitura da História do Holocausto por meio da escritura autobiográfica das vítimas. Disponível

em: http://www.revistafenix.pro.br/PDF20/ARTIGO_13_Vera_Silveira_Regert_FENIX_JUL_AGO_SET_2009.pdf Acesso em: 09 jan. 2014.

SANTIAGO, Pedro. CERQUEIRA, Célia. PONTES, Maria Aparecida. Por dentro da História. $3.1^{\text {a }}$ Ed. - São Paulo: Edições Escala Educacional S/A, 2010.

SERIACOPI, Gislane Campos Azevedo. SERIACOPI, Reinaldo. História: Volume único. 1ª Ed. - São Paulo: Ática, 2005.

Vários Autores. Projeto Araribá: história Ensino fundamental. $9^{\circ}$ ano. $2^{\text {a }}$ Ed. - São Paulo: Moderna, 2007. 